\title{
The influence of processing parameters on the ultrasonic degassing of molten AlSi9Cu3 aluminium alloy
}

\author{
Hélder Puga $^{\text {a }}$, Joaquim Barbosa ${ }^{\text {a,* }}$, E. Seabra ${ }^{\text {a }}$, S. Ribeiro ${ }^{b}$, M. Prokic ${ }^{c}$ \\ a Universidade do Minho, Departamento de Engenharia Mecânica, 4800-058 Guimarães, Portugal \\ ${ }^{\mathrm{b}}$ FEUP, Departamento de Engenharia Metalúrgica e de Materiais, 4200-465 Porto, Portugal \\ c MP Interconsulting, 2400 Le Locle, Switzerland
}

\section{A R T I C L E I N F O}

\section{Article history:}

Received 20 October 2008

Accepted 8 January 2009

Available online 11 January 2009

\section{Keywords:}

Casting

Porosity

Metals and alloys

Metallurgy

\begin{abstract}
A B S T R A C T
The effect of high intensity ultrasound on the degassing of AlSi9Cu3 alloy using the novel MMM (Multi-frequency Multimode Modulated) technology was studied. Different ultrasonic parameters (power and frequency), melt temperature and processing times were tested and their influence on the degassing efficiency evaluated. RPT (Reduced Pressure Test) was used to evaluate the hydrogen content in the alloys and the samples porosity level and density. For the experimental conditions used in this research, it was found that ultrasonic frequency has no influence on the hydrogen removal rate that, in turn, strongly depends on the ultrasonic power, the processing time and the melt temperature. The experimental results suggest that the MMM ultrasonic technology is an important improvement to the fixed-frequency ultrasonic systems by significantly decreasing the processing time to achieve a quasi-equilibrium hydrogen concentration in aluminium melts.
\end{abstract}

(c) 2009 Elsevier B.V. All rights reserved.

\section{Introduction}

The main source of gas porosities in aluminium castings is hydrogen, which is the only gas with significant solubility in molten aluminium [1]. At solidification point, a large drop in solubility occurs, leading to hydrogen precipitation and development of gas porosities. For this reason, the hydrogen content in a molten alloy must be kept as low as possible, especially when dealing with high-strength casting alloys [1,2].

Several methods are usually used to reduce the hydrogen content in aluminium melts, all of which generate great amount of slag and present an important environmental impact.

Ultrasonic degassing is a possible way to overtake such drawbacks and to improve hydrogen removal. When a liquid metal is submitted to high intensity ultrasonic vibrations, the alternating pressure above the cavitation threshold creates numerous cavities in the liquid metal $[3,4]$. Cavitation intensifies mass transfer processes accelerating the diffusion of hydrogen from the melt to the developed bubbles. As acoustic cavitation progresses with time, adjacent bubbles touch and coalesce, growing to a size sufficient to allow them to rise up through the liquid, against gravity, until reach surface $[3,4]$.

The majority of the traditional ultrasonic applications are based on fixed-frequency, well-tuned ultrasonic sources, where a large number of designs and matching parameters must be respected [3-6]. Extensive field tests conducted by experts in ultrasonics have demonstrated that in order to achieve high efficiency, the ultrasonic systems must be well tuned to the load $[4,7]$. Since most ultrasound units work inherently in

\footnotetext{
* Corresponding author. Tel.: +351 253510220/59; fax: +351 253516007 E-mail address: kim@dem.uminho.pt (J. Barbosa).
}

non-stationary conditions, they have to, in theory, continuously adapt themselves to the load to maximize the efficiency, which is difficult to achieve with the fixed-frequency units. To meet this challenge, novel MMM signal processing techniques have been developed by MP Interconsulting [7-9]. This technique has the potential to synchronously excite many vibrating modes through the coupled harmonics and sub harmonics in solids and liquid containers to produce high intensity multimode vibrations that are uniform and repeatable. Such sonic and ultrasonic driving creates uniform and homogenous distribution of cavitation and acoustical activity on a surface and inside the vibrating system, while avoiding the creation of stationary and standing waves, so that the whole vibrating system is fully agitated.

This paper presents an experimental study developed in order to characterize the influence of different processing parameters on the degassing efficiency of AlSi9Cu3 aluminium alloy using a MMM based ultrasonic equipment.

\section{Experimental procedure}

The main components of the MMM ultrasonic system used in this research consist of a high power ultrasonic converter, an acoustic

Table 1

Ultrasonic degassing conditions

\begin{tabular}{ll}
\hline Ultrasonic frequency [kHz] & $18.5-19.8-22.0$ \\
Electric power [W] & $250-450-750$ \\
Degassing time [minute] & $0-1-3-5$ \\
Melt temperature $\left[{ }^{\circ} \mathrm{C}\right]$ & $650-700-750$ \\
Ambient humidity [RH] & $58 \pm 5$
\end{tabular}




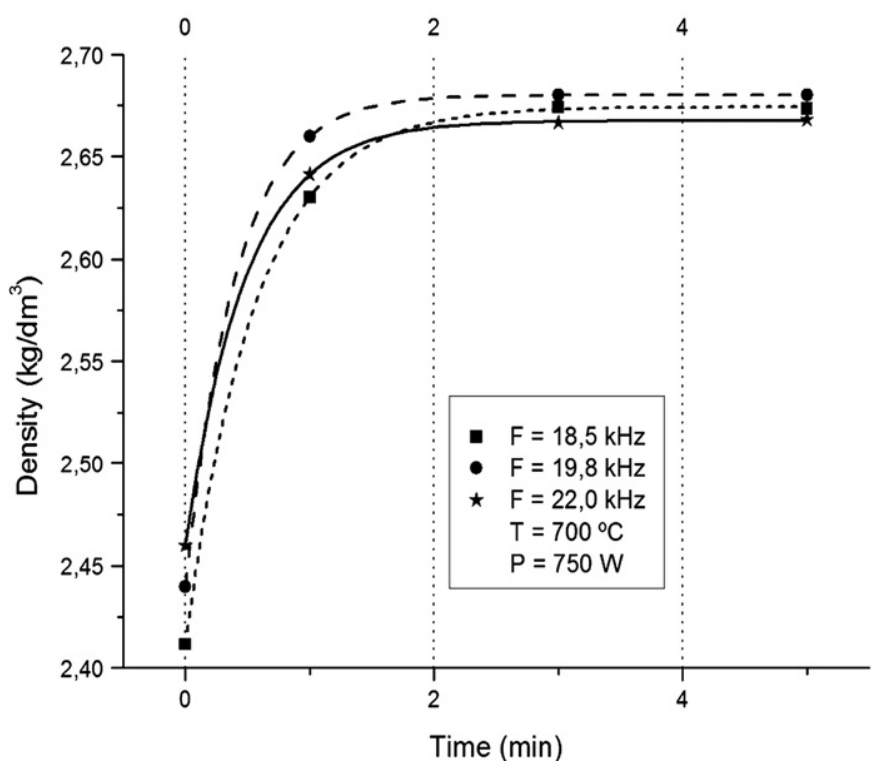

Fig. 1. Density of the AlSi9Cu3 alloy as a function of ultrasonic frequency, for $750 \mathrm{~W}$ electric power and $700{ }^{\circ} \mathrm{C}$ melt temperature.

wave-guide and radiator, a sweeping-frequency, adaptively modulated waveform generated by an MMM ultrasonic power supply. The equipment is fully controlled through Windows compatible software developed by MPI. Optimal ultrasonic parameters (sweeping and fswm = frequency shift with modulation) for the selected resonant frequency and electric power are adjusted in order to produce the highest acoustic amplitude and the largest frequency spectrum in the metal, which is monitored with a specifically implemented feedback loop.

Melting stocks of AlSi9Cu3 alloy weighing $4 \mathrm{~kg}$ were melted in a resistance furnace equipped with a $170 \mathrm{~mm}$ diameter and $180 \mathrm{~mm}$ height SiC crucible. Melt temperature was controlled within an accuracy of $\pm 10{ }^{\circ} \mathrm{C}$. Degassing was carried out under different processing conditions according to Table 1 using a $60 \mathrm{~mm}$ diameter radiator made of a titanium-based material. Due to the well-known difficulty to measure accurately the hydrogen content in aluminium alloys, results evaluation was based in the measurement of samples density, which is directly related to the samples hydrogen content. For every experiment, the Reduced Pressure Test (RPT) and the apparent density measurement method were used to evaluate the samples density $[1,10]$.

\section{Results and discussion}

\subsection{Effect of resonant frequency and degassing time}

Fig. 1 shows the effect of resonant frequency on the samples density for different degassing times at $700{ }^{\circ} \mathrm{C}$ melt temperature and using $750 \mathrm{~W}$ electric power. The maximum alloy density $\left(2.67 \mathrm{~kg} \times \mathrm{dm}^{-3}\right)$ was obtained after 2-minute ultrasonic processing (although after $1 \mathrm{~min}$ it is already about $98.5 \%$ of the maximum value), for every evaluated frequency, suggesting that for the experimental conditions used in this research this parameter has no apparent influence on the degassing efficiency.

It is also clear from Fig. 1 that the kinetics of ultrasonic degassing is time dependent and changes as hydrogen is being removed from the melt, confirming the results of other researchers [3,6]. After a high density increase in the first minute, which is a consequence of a high hydrogen removal rate, the density increasing rate slows down which means that a hydrogen content steady-state plateau is being reached. For longer degassing times the density remains constant, and the difference/balance to the theoretical alloy density is only due to solidification defects. This behaviour is due to the mechanism of hydrogen removal from aluminium melts and the effect of acoustic cavitation on that mechanism. In fact, due to the extremely large number of very small bubbles developed in the molten alloy by cavitation, diffusion of hydrogen towards them is very fast. As a consequence, the number of hydrogen atoms in the molten alloy decreases at the same rate, slowing down the diffusion mechanism of hydrogen, thus degassing and density increasing rates.

\subsection{Effect of electric power}

In Fig. 2a) the effect of electric power on the samples density increasing rate is presented for different degassing times at $700{ }^{\circ} \mathrm{C}$, for a frequency of $19.8 \mathrm{kHz}$. It seems that the degassing efficiency is power dependent, and that this has a significant influence on both the degassing rate and the maximum alloy density.

For $750 \mathrm{~W}$, a density steady-state plateau of $2.68 \mathrm{~kg} \times \mathrm{dm}^{-3}$ was obtained after $2 \mathrm{~min}$ ultrasonic processing. Lower electric power inputs not only decrease the maximum alloy density, but also slow down the hydrogen removal rate. For $450 \mathrm{~W}$, the density steady-state plateau was about $2.64 \mathrm{~kg} \times \mathrm{dm}^{-3}$, which was achieved only after $3 \mathrm{~min}$ ultrasonic processing. For lower power values the hydrogen removal efficiency is very low, as it happened using $250 \mathrm{~W} .4 \mathrm{~min}$ were not enough to reach the density steadystate plateau, and the alloy density did not increase for more than $2.55 \mathrm{~kg} \times \mathrm{dm}^{-3}$, which is unacceptable in foundry practice. The influence of the electric power level on the kinetics of hydrogen removal can be easily understood by observing the amplitude of the acoustic waves inside the molten alloy presented in Fig. 2b), which is a valuable indicator to the effective development of cavitation in the liquid metal [4]. In those melts treated in a well-developed cavitation regime as suggested by Fig. $2 \mathrm{~b}$ for $750 \mathrm{~W}$, the high density of cavitation bubbles and the partial displacement of drops of liquid in the treated volume develop strong acoustic streams that improve the coagulation of a)

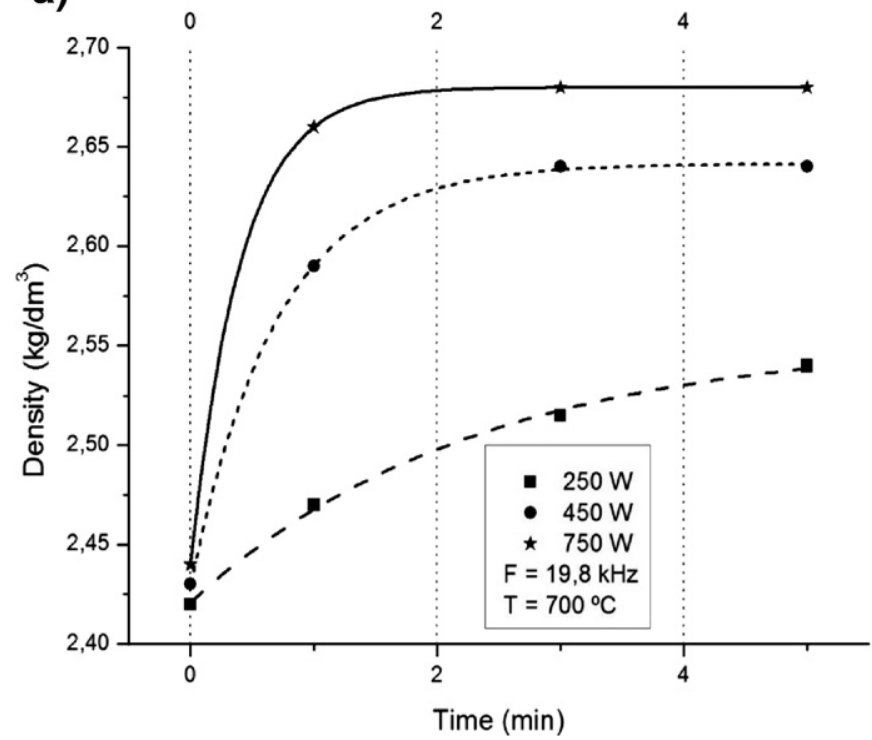

b)
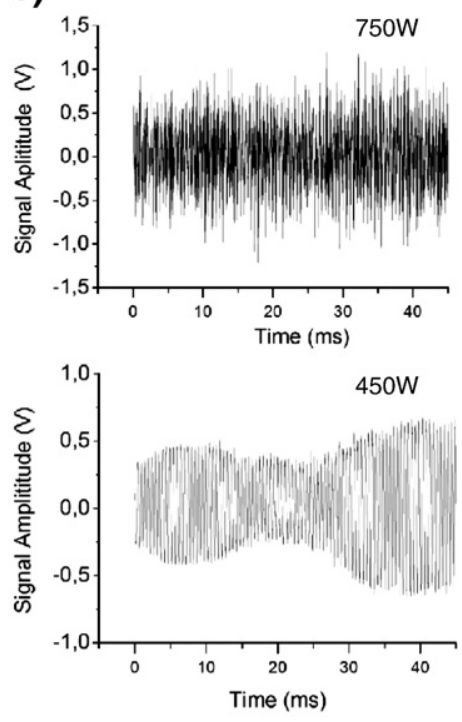

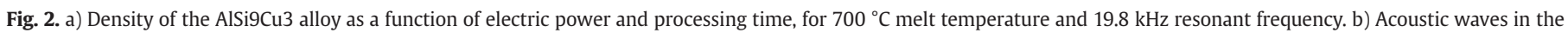
molten metal for 750 and $450 \mathrm{~W}$ electric energy. 


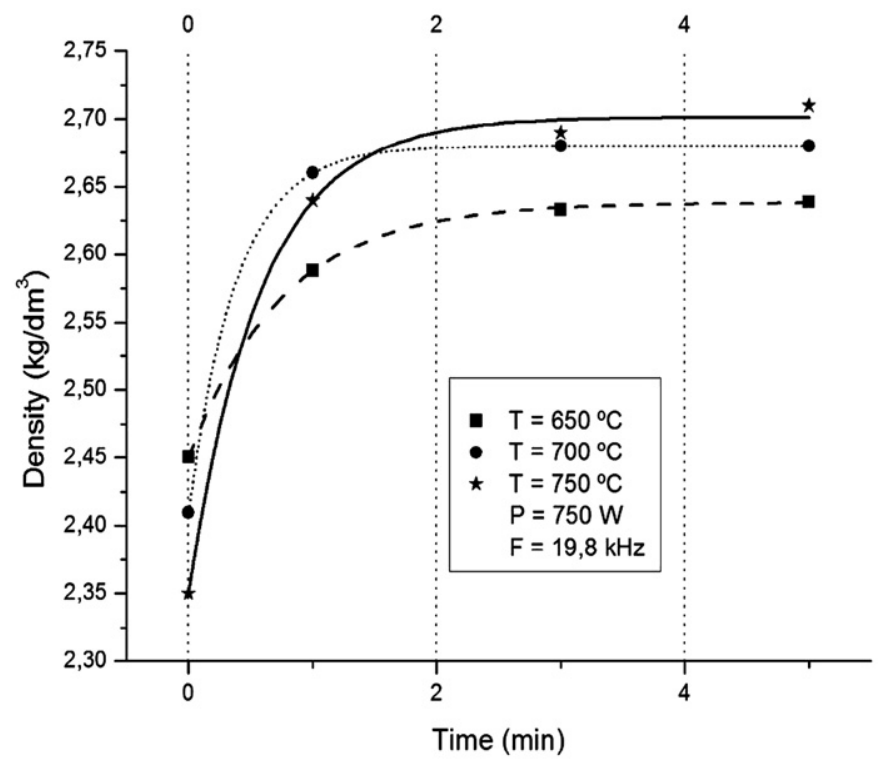

Fig. 3. Density of the AlSi9Cu3 alloy as a function of melt temperature and processing time, for $19.8 \mathrm{kHz}$ resonant frequency and $750 \mathrm{~W}$ electric power.

separate bubbles of hydrogen and its floating to the surface of the pool [4], and consequently, a raise of the degassing and density increasing rates.

\subsection{Effect of melt temperature}

For temperatures below $750{ }^{\circ} \mathrm{C}$, the degassing rate was found to be sensitive to melt temperature, increasing directly with it (Fig. 3). Experiments above $750{ }^{\circ} \mathrm{C}$ were not carried on because above that temperature the hydrogen solubility in Al alloys is very high. On the other hand, in industrial practice aluminium alloys are usually poured at lower temperatures, thus melt treatment above $750{ }^{\circ} \mathrm{C}$ would be high energy consuming and inadequate for foundry practice.

Experimental results show that for melt temperatures of 700 and $750{ }^{\circ} \mathrm{C}$ the hydrogen removal and density increasing rates, as well as the density steady-state plateaus are quite similar (2.68 and $2.7 \mathrm{~kg} \times \mathrm{dm}^{-3}$ respectively). For lower melt temperatures the degassing rate slows down, and the maximum alloy density achieved is about $2.63 \mathrm{~kg} \times \mathrm{dm}^{-3}$. This behaviour can be explained by two reasons. One is that the decrease of the diffusion coefficient of hydrogen in liquid metals as temperatures drops slows down the diffusion of hydrogen from the liquid to the cavitation bubbles. The other is that the decrease of the melt viscosity makes more difficult the pulsation of cavitation bubbles, their coagulation and floating to the surface.

\section{Conclusions}

- Ultrasonic degassing can be an efficient process to degas molten aluminium alloys. For melting charges up to $4 \mathrm{~kg}$, acceptable degassing is achieved after 2 min ultrasonic treatment, although after $1 \mathrm{~min}$ the alloy density is already about $98.5 \%$ of the maximum value.

- The degassing efficiency depends on the electric energy that is converted into acoustic energy, but is not affected by the resonant frequency.

- For melt temperatures between 700 and $750{ }^{\circ} \mathrm{C}$ the degassing rate and the final alloy density don't change significantly with temperature. Melt treatment at lower temperatures slows down the degassing rate and leads to unacceptable low levels of alloy density.

- When compared with the traditional fixed-frequency ultrasonic units, the MMM ultrasonic technique seems to improve significantly the ultrasonic degassing process by increasing the final alloy density and the degassing rate.

\section{Acknowledgments}

This research was supported by FCT-Portuguese Foundation for Science and Technology and was developed on the aim of the research project PTDC/EME-TME/64663/2006.

\section{References}

[1] Gruzleski JE, Closset BM. The Treatment of Liquid Aluminium-Silicon Alloys. 1st Ed. Des Plaines AFS; 1990.

[2] Meidani ARN, Hasan M. J Mater Process Technol 2004;147:311-20.

[3] Xu H, Jian X, Meek TT, Han Q. Mater Lett 2004;58:3669-73.

[4] Eskin GI. Ultrasonic Treatment of Light Alloy Melts. 1st Ed. Amsterdam: Gordon and Breach Science Publishers; 1998.

[5] Jian X, Xu H, Meek TT, Han Q. Mater Lett 2005;59:190-3.

[6] Xu H, Meek TT, Han Q. Mater Lett 2007;61:1246-50.

[7] Prokic M. UIA Conference 2001, Atlanta, USA.

[8] Prokic M. European Patent Application EP 1238715A1, 2001

[9] Prokic M. French Patent Application 2743929 (No d'enregistrement national: 96 $01029) ; 1997$.

[10] Dispinar D, Campbell J. Int J Cast Met Res 2004;17:280-6. 